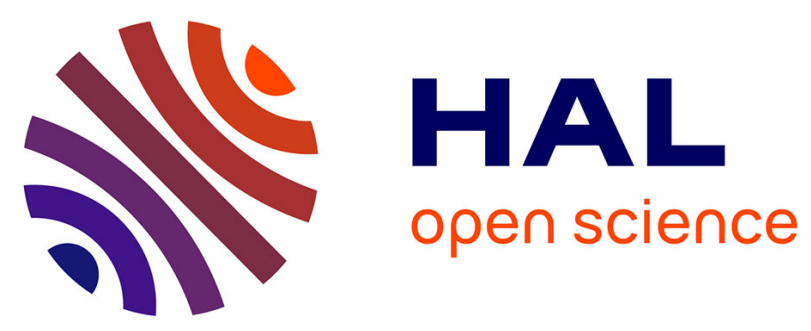

\title{
Developing Multimedia Enhanced Content to Raise HIV/AIDS Awareness to Children
}

\author{
Patricia Makuru, Fatuma Simba, Ellen Kalinga
}

\section{To cite this version:}

Patricia Makuru, Fatuma Simba, Ellen Kalinga. Developing Multimedia Enhanced Content to Raise HIV/AIDS Awareness to Children. 15th International Conference on Social Implications of Computers in Developing Countries (ICT4D), May 2019, Dar es Salaam, Tanzania. pp.433-444, 10.1007/978-3030-19115-3_36. hal-02281322

\section{HAL Id: hal-02281322 \\ https://hal.inria.fr/hal-02281322}

Submitted on 9 Sep 2019

HAL is a multi-disciplinary open access archive for the deposit and dissemination of scientific research documents, whether they are published or not. The documents may come from teaching and research institutions in France or abroad, or from public or private research centers.
L'archive ouverte pluridisciplinaire HAL, est destinée au dépôt et à la diffusion de documents scientifiques de niveau recherche, publiés ou non, émanant des établissements d'enseignement et de recherche français ou étrangers, des laboratoires publics ou privés. 


\title{
Developing Multimedia Enhanced Content to Raise HIV/ AIDS Awareness to Children
}

\author{
Patricia Makuru ${ }^{1}$, Fatuma Simba ${ }^{2[0000-0002-6575-759 x]}$ \\ and Ellen Kalinga ${ }^{2}$ \\ ${ }^{1}$ Tanzania Broadcasting Coorporation (TBC), Tanzania. \\ pmakuru@gmail.com \\ ${ }^{2}$ University of Dar es Salaam (UDSM), Tanzania. \\ fatmasimba@gmail.com and ellenakchale@gmail.com
}

\begin{abstract}
It is estimated that more than two-thirds (70\%) of all the 35 million people living with Human Immunodeficiency Virus (HIV) in the world are in Sub-Saharan Africa. Tanzania as one of the country in sub-Sahara region is no exceptional, more than 60 percent of all new HIV infections in Tanzania occur among young people. While almost all children in Tanzania aged 15 years and below have heard about HIV/AIDS, less than half have enough knowledge to protect themselves against infections. It is known that HIV/AIDS is taught in primary schools, although majority of the pupils demonstrated a very low level of knowledge about HIV/AIDS. This raised a concern on the effectiveness of HIV/AIDS and life skills education in primary schools. Information and Communication Technology (ICT) has a great potential for HIV/ AIDS education to children because they like and enjoy to use ICT resources for entertainment, learning, networking and communication. Hence, it is important to apply technology for educational in teaching HIV/AIDS through the use of multimedia contents in accordance to the local context of Tanzanian curriculum for primary schools. Therefore, the main objective of this paper is to develop multimedia enhanced contents to raise HIV/AIDS awareness to children. ADDIE model, Adobe Flash Professional 5, Action Script programming language and articulate storyline2 authoring tool, were used in the development of multimedia enhanced contents. Results show that level of HIV/AIDS knowledge among pupils after using the interactive multimedia has been enhanced in the tested three knowledge areas (causes, prevention and effects). Results in this paper suggest that, multimedia enhanced contents can be used to complement text book based learning approach in enhancing HIV/AIDS awareness for children in primary schools in Tanzania.
\end{abstract}

Keywords: HIV/AIDS, Interactive Multimedia Content, Tanzania, Primary Schools

\section{Introduction}


It is estimated that more than two-thirds (70\%) of all the 35 million people living with $\mathrm{HIV}$ in the world are in Sub-Saharan Africa [1]. The region has just over 10 percent of the world's population, but constitutes 70 percent of all people living with HIV worldwide. Young people are the most affected by HIV/AIDS epidemic in Tanzania [2]. For example, it is estimated that more than 60 percent of all new HIV infections in Tanzania occur among young people [3]. Statistics also show that $17 \%$ of the child population in Tanzania aged between 0 and 14 years are vulnerable to HIV infection, poverty and associated threats to well-being, with $5 \%$ characterized as most vulnerable. While almost all children aged 15 years and below have heard about HIV/AIDS, less than half have enough knowledge to protect themselves against infection. There are many factors that lead to HIV/AIDS epidemic spread among children in Tanzania and other developing countries which include: early marriages, early sex debut and some socio-cultural beliefs such as female genital mutilation, spousal inheritance laws, obligatory marital sex and the encouragement to multiple sexual partners among men. However, the major cause of spread of HIV/AIDS epidemic is lack of information about the disease [4].

Bilinga and Mabula [5] indicated that 450 standard V, VI and VII pupils from 10 schools in Morogoro Municipality shows that, though majority of pupils reported to have been taught about HIV/AIDS and related subjects, majority of them demonstrated a very low level of knowledge about HIV/AIDS [6]. This raised some questions about the effectiveness of HIV/AIDS and life skills education in schools. On the basis of the study findings, it is recommended that there should be a review of the school curriculum with a view of strengthening teaching of HIV/AIDS and life skills education [7]. Moreover, there are a good number of organizations in Tanzania engaged in one way or another in fighting against the epidemic, these include Tanzania AIDS Society (TAS), Tanzania Commission for AIDS (TACAIDS) in collaboration with the National AIDS Control Programs in the Ministry of Community Development, Gender and Children , Universities and other Higher Learning Institutions in the country, International Development Partners on AIDS, Community Based Organizations, Non-Governmental Organizations, Civil Societies and government sectors [3]. All these efforts are focusing on creating HIV/AIDs preventive awareness in Tanzania. Apart from all these efforts, still HIV/AIDs knowledge or awareness among young people remain inadequate [2].

PMO [3] stated that in order to protect young people against HIV/AIDS, the children need information, skills, children friendly health services, and a safe and supportive environment. Rishante [8] stated that the study of HIV/AIDS is not easy to implement with the existing common teaching and learning methods. However, Information and Communication Technology (ICT) resources hold great potential for HIV/ AIDS education for children because children like to use ICT resources for entertainment, learning, networking and communication [9]. ICT-based teaching and learning approaches are most likely to motivate children to learn about HIV/AIDS education in addition to the use of textbooks [10]. One of the advantages of the ICT is in making multimedia teaching and learning contents, in which the multimedia contents can be used as the solution to improve the student motivations in learning [11]. Moreover, development of multimedia content allows the integration of multiple multimedia ele- 
ments that could ease the study and understanding of HIV/AIDS thus enriching the learning environment. Technology can change the paradigm of teacher-centered to student-centered [11].

It is important to apply technology for educational applications in teaching HIV/ AIDS in classrooms through the use of multimedia content in accordance to the local context of Tanzanian curriculum for primary schools. Therefore, the main objective of this study is to develop multimedia enhanced content to raise HIV/AIDS awareness to children.

\section{Literature Review}

\subsection{Multimedia and Children Learning}

Childhood Education is an important stage in the child's educational life. If a teacher succeeds in framing a sound base and making the entire concept clear to a child then in future the student will be able to grasp difficult thing easily [12]. ICT has the potential to raise the quality of education in childhood. Multimedia as part of ICT, empowers the teaching and learning processes by means of increased interaction between teachers and students [13]. Multimedia enriches the learning contents by providing different tools for learning the same lesson. It allows integration of multiple multimedia elements that could ease the study and understanding of a subject matter thus enriching the learning environment. The process of knowledge acquisition becomes more efficient when the learners experience an event through a multimedia contents such as simulation[14]. Multimedia overcomes the barriers of time and space for educating multi-disciplinary masses.

Skills related to creative expression and aesthetic appreciation painting, drawing can be better done in computer instead of paper and color pencil. Sensitivity towards beauty can be encouraged by PowerPoint presentation showing beautiful collections of birds, flowers, animals [15] that are attractive to children. Different types of multimedia contents such as audio, video, text, images, animations, interactive texts, exciting feedbacks (positive or negative) are highly significant on children's academic performances and all round development [16].

\subsection{Related Works}

The emergence of information technology has become an integral part towards the study of HIV/AIDS. In relation to that, a lot of efforts and steps have been taken to increase the students' quality of learning and understanding in HIV/AIDS courses [17].

Kaewkiriya [18] developed multimedia game for multimedia technology lesson with the purpose to assist students in learning the subject. The developed multimedia game was used to make the lesson more interesting and at the same time to provide students with real example of how multimedia works. The effectiveness of the developed game was studied by comparing results of the same test from students taking conventional class-room lectures and those using the developed multimedia game in Thailand. Results showed that those using the developed multimedia game performed better at the statistical significance level of 0.05 . 
Kizito \& Suhonen [17] developed computer games and online lessons with discussion forum designed using open source learning management system (Moodle). The digital learning objects were for HIV/AIDS prevention education in schools. The aim was to design digital learning environment and evaluate its acceptance with students of age range from 13 to 19 years and teachers in Uganda. Hence the experimentation of these games and online lessons in schools and the subsequent evaluation shows acceptance of games and online lessons.

Krishna et al., [19] aimed at determining whether health outcomes of children who have asthma can be improved through the use of an Internet-enabled interactive multimedia asthma education program. A total of 228 children with asthma were randomly assigned to control and intervention groups. Children and caregivers in both groups received traditional patient education. Intervention group participants received additional self-management education through the interactive multimedia program for asthma control and tracking. Results showed that interactive multimedia program for asthma control and tracking significantly increased asthma knowledge of children and caregivers, it decreased asthma symptom days (81 vs 51 per year), and decreased number of emergency department visits (1.93 vs 0.62 per year) among the intervention group participants. The conclusion was supplementing conventional asthma care with interactive multimedia education can significantly improve asthma knowledge and reduce the burden of childhood asthma.

Chuang and Chen [10] investigated whether computer-based video games facilitate children's cognitive learning in Taiwan. In comparison to traditional computer-assisted instruction, the study explored the impact of the varied types of instructional delivery strategies on children's learning achievement. One major research null hypothesis was tested: there are no statistically significant differences in students' achievement when they receive two different instructional treatments: (1) traditional computer-assisted instruction; and (2) a computer-based video game. Results indicate that computer-based video game playing not only improves participants' fact/recall processes but also promotes problem-solving skills by recognizing multiple solutions for problems.

From the existing related work, it has been note that technology enhanced learning improves the learning process. The existing related study on HIV/AIDS focuses on examining acceptance of developed multimedia game and online lessons for students aged 13-19 years and teachers. To the best of our knowledge, there is no study that examined if multimedia contents can enhance HIV/AIDS awareness to children in Tanzania. Moreover, most of the existing multimedia content are context based on a certain culture. They are not designed on the ways Tanzanian children learn, and also not tested with children to assure that the multimedia content is fit for that age group. They also lack features for monitoring of children learning progress and do not provide feedback to their teachers or parents [13]. Walsham and Sahay [20] argue that computer based applications that are currently used in developing countries such as Tanzania originates from the Unites States of America (USA) and the United Kingdoms (UK). Subsequently, educational software packages are mainly based on the curricula and preferred pedagogies of these countries. This includes the existing HIV/ AIDS multimedia content available on the Internet. The existing multimedia contents 
lack local context to match with the Tanzanian curriculum for primary schools. Therefore this paper filled this gap by developing multimedia enhanced contents that enabled children to learn HIV/AIDS awareness education in the context of Tanzanian curriculum for primary schools.

\section{Methodology}

\subsection{Study Area and Sample Size}

Participants chosen for this study were selected through simple random sampling. Two primary schools were selected, one public (Karakata primary school) and one private (Libermann primary school) with computer laboratory or computers and are easily reachable in Ilala district, Dar es Salaam region. The target population were standard three (3) to standard six (6) pupils who are taught about HIV/AIDS. The study group is composed of 40 pupils and 4 teachers from Libermann and 40 pupils and 4 teachers from Karakata, which sum up to 80 pupils and 8 teachers.

\subsection{Data Collection and Analysis}

Primary source of data involved children/pupils, teachers and organizations dealing with HIV/AIDs issues like TACAIDS, Ministry of Education and TIE. Secondary source of data was through learning what curriculum offers, search from Internet how interactive learning content are developed and other related publications. Tools used were interviews, observation, focus group discussion, document review and questionnaires for collecting both quantitative and qualitative data. It also involved studying pedagogies in primary school and understanding of HIV/AIDS content from TIE syllabus as the primary source of data and identification of requirements for developing the HIV/AIDS multimedia content as per the Tanzanian context.

The prototyped multimedia enhanced content was taken to pupils from selected primary schools where secondary data was collected. The pupils and teachers involved in the study were asked to fill in the questionnaire that was intended to evaluate the developed HIV/AIDS multimedia enhanced contents. Microsoft Excel was applied as an analysis tool. The developed multimedia contents were uploaded to the learning management system called, Tanzania Secondary School e-learning (TanSSeL) system, then students were given access to learn and do self-assessment on the understanding of HIV/AIDS multimedia content. The LMS provided a statistical assessment of the pupils' performance. 


\subsection{Method for Educational Multimedia Content Development}

This paper adopted ADDIE instructional design model for contents design and development. ADDIE is an instructional design model which is valid for any kind of education material development. It provides a step-by-step process which assists in building the prototype. Its name is an acronym of the capital letters of the words: Analyze, Design, Develop, Implement, and Evaluate as shown in Figure 1.

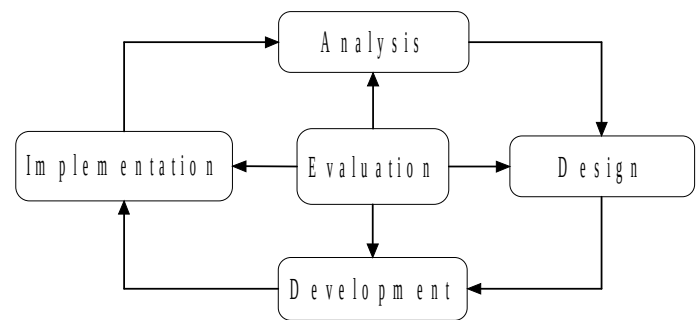

Fig. 1. ADDIE Instructional Design Model (Source: [21] )

\section{HIV/AIDS Multimedia Contents Development and Evaluation}

In developing the multimedia enhanced content, steps of ADDIE model were adopted. Adobe Flash Professional 5 platform, Action Script programming language and articulate storyline2 authoring tool, were used in the development of the multimedia content. The development of the multimedia enhanced contents involved teachers and pupils where the development process was characterized by stories /scenarios explaining what the multimedia enhanced content needs to do for the users. Demonstrations of the releases/versions were done repeatedly. In each iteration, units are tested before integration and evaluation tests were conducted to see whether the multimedia enhanced satisfies the expectations and needs of the users. The developed multimedia contents were uploaded and can be accessed online in TanSSeL (http://tanssel.ecse.udsm.ac.tz/moodlecvs/course/view.php?id=76) as seen in the figure 2. The same content is packed in a CD. For the user to be able to use the multi media content, he/she has to register and thereafter login into the system. All users' information and privileges are stored in the system database. 


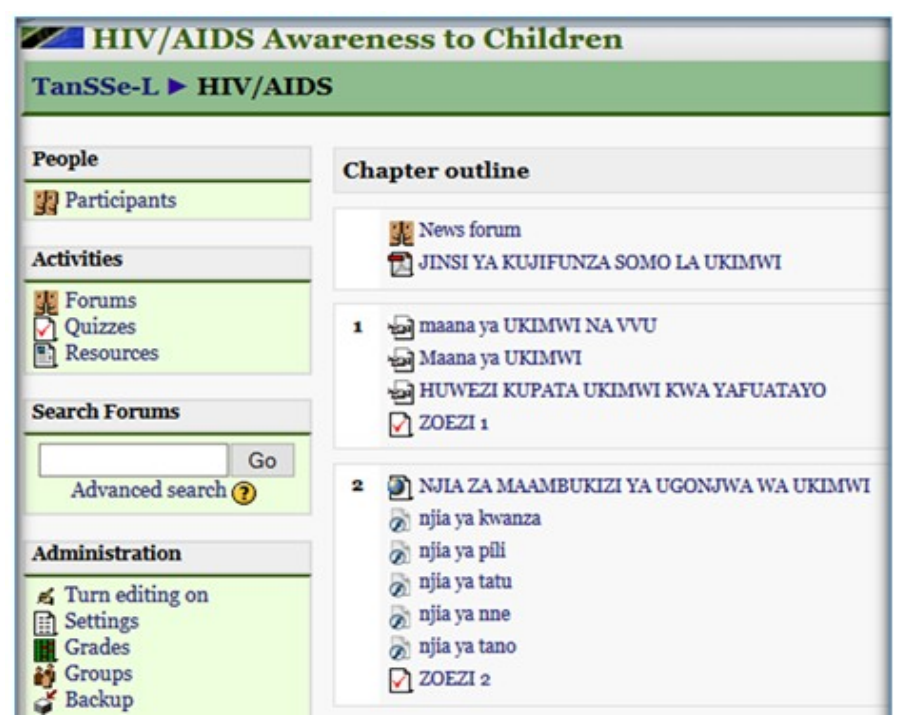

Fig. 1. A Web Page of the Multimedia Enhanced Content in the TanSSeL System

Once a pupil is logged into the system, he/she can select a topic of interest, then clicks the play button so as to start learning from the multimedia enhanced contents. While learning a pupil can either pause the content, stop or rewind the multimedia content on the point where repetition is needed. The developed contents cover topics in i) Meaning and causes of HIV/AIDS ii) Symptoms iii) Transmission means v) Prevention and v) advises for people living with HIV/AIDS. Figure 3 shows the symptoms of a person suffering from HIV. These symptoms can be evident from a few days to several weeks after being infected by HIV/AIDS. Symptoms can be fever, coughing, headache, diarrhea, nausea and vomiting, fatigue.

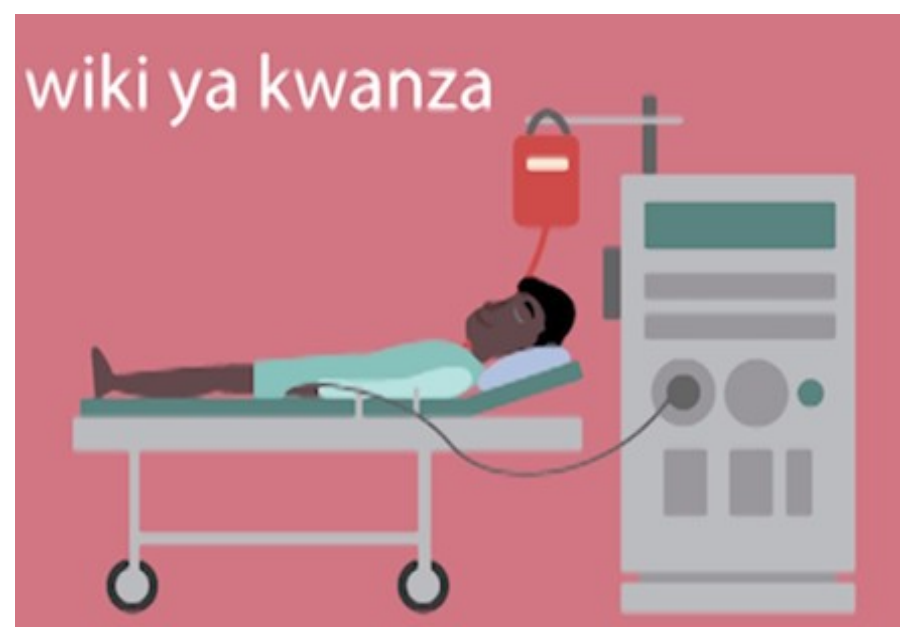

Fig. 3. Fever is one of the symptoms of HIV/AIDS 
One can get or transmit HIV/AIDS only through specific activities. Such as transfusion of blood which is not tested and is not safe as shown in figure 4. HIV/AIDS can be as well be transmitted through unsafe sexual behaviors as in figure 5 , or by sharing of sharp objects like razor blade, needle or syringe.

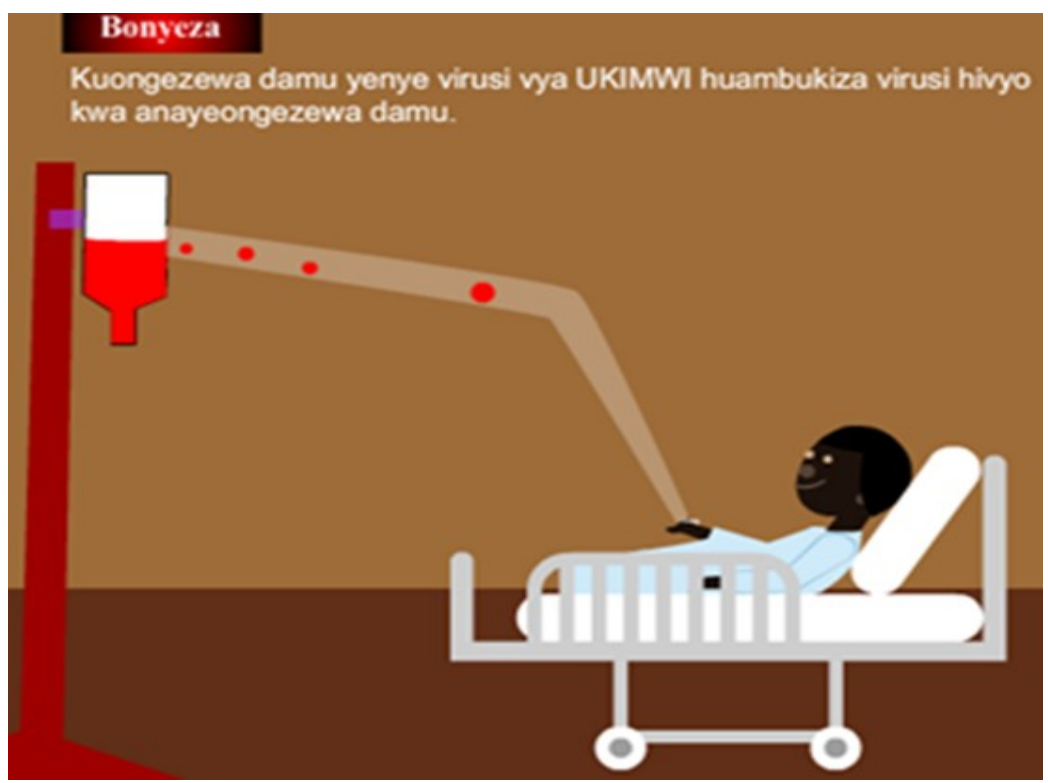

Fig.4. Unsafe blood transfusion can cause HIV/AIDS

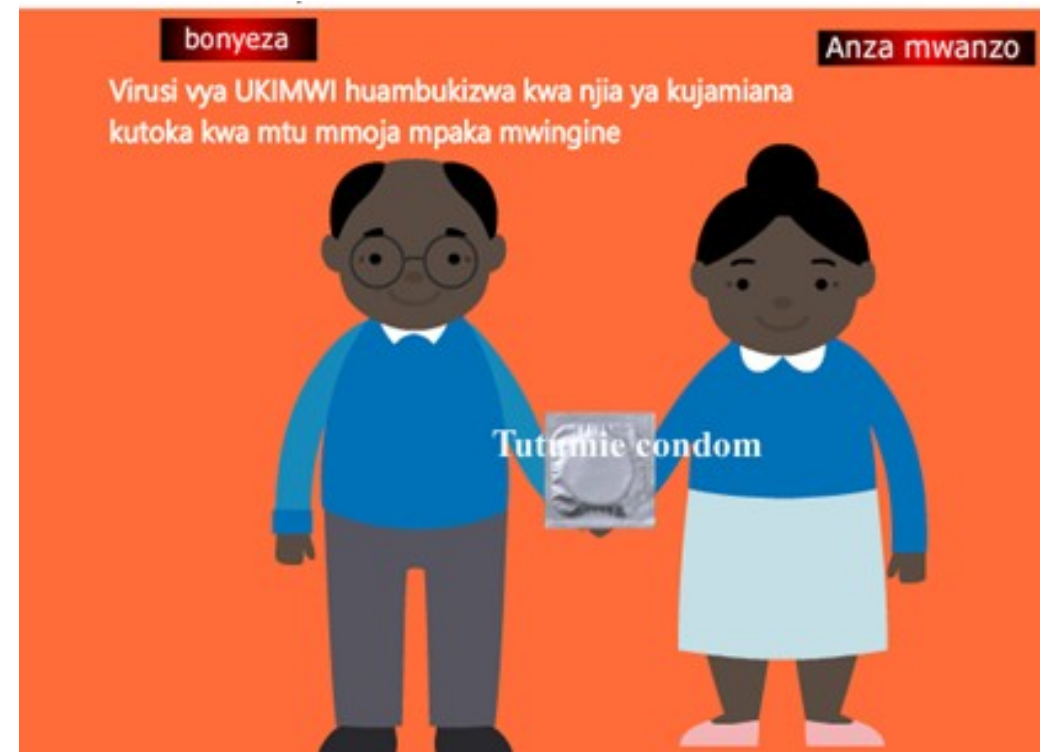

Fig.5. Unprotected sex can cause HIV/AIDS 
After learning the pupil will be required to attempt the exercises found at the end of each topic. The exercise will be automatic marked, if the pupil has scored less than the set pass mark, then he/she will be required to repeat the exercise for the wrong answered questions. Until a pupils scored the required pass marks, then he/she will be required to move to the next level, otherwise the pupil won't be allowed to move to the next level.

\subsection{Evaluation of the Developed Multimedia Contents}

The developed multimedia content were used for testing/evaluation by pupils from two primary schools at Ilala district in Dar es Salaam; 40 pupils from Libermann primary school and 40 pupils from Karakata primary school, all pupils were from grade $\mathrm{V}$ and VI. After using the contents for three months, all 80 pupils participated in the evaluation process of the developed multimedia enhanced contents by filling in questionnaires. The questionnaire uses the 5-point Likert Scale approach. Some of the aspects considered in the questionnaire for evaluation were (i) Level of Difficulty/Easy of use (ii)Usefulness (iii)Effectiveness.

Effectiveness of the developed interactive multimedia content in HIV/AIDS awareness to children was evaluated by using pre-test and post-test approaches. The pre-test took part in January 2018 and the Post-test took part in September 2018 after pupils have been left to use the interactive multimedia in their computers. The same set of questions which were used during the pre-test was also used in the post-test as well as the same pupils who participated on the pre-test were the one who also participated on the post-test. Knowledge in HIV/AIDS awareness was measured in terms of i) Causes of HIV/AIDS ii) Ways of preventing against HIV/AIDS iii) Effects of HIV/AIDS.

\section{Results and Discussion}

\subsection{Level of Difficulty of the Multimedia Enhanced Content}

Studies show that if the technology is not easy to use, users will spend more time learning how to use it rather than learning the content [22]. Therefore, it was necessary to gather feedback from pupils and teachers how they perceived the multimedia enhanced content in terms of the level of difficulty. Pupils and teachers were asked to rate the level of difficulty of the multimedia enhanced content on 5-point Likert Scale [1=Very Difficult: 2=Difficult: 3=Neutral: 4=Easy: 5=Very Easy]. Overall, the majority of pupils and teachers (85\%) indicated that the multimedia enhanced content was easy to use while $5 \%$ indicated that the multimedia enhanced content was difficult to use.

\subsection{Multimedia Enhanced Content Usefulness}

In order to find out if users found multimedia enhanced content to be useful in facilitating HIV/AIDS awareness creation in children, users were asked to rate on 5-point Likert Scale [1=Strongly Disagree: 2=Disagree: 3=Neutral: 4=Agree: 5=Strong Agree]. The obtained result indicated that the majority of users $80 \%$ of pupils agreed 
that using multimedia enhanced content enabled to rise pupils’ HIV/AIDS awareness. On the other hand, a minority of users $2.5 \%$ of pupils indicated that the multimedia enhanced content did not facilitate HIV/AIDS awareness to children.

\subsection{Effectiveness of the Multimedia Enhanced Content}

The effectiveness of the developed multimedia enhanced contents was evaluated by administering pre-test and post-test to pupils.

Pre-Test Results. Pupils filled out 10-item questionnaires to investigate the level of knowledge regarding HIV/AIDS awareness in terms of causes of HIV/AIDS, ways of preventing against HIV/AIDS and Effects of HIV/AIDS. Out of the 80 pupils who did the test, $60.8 \%$ from Libermann, 54.2\% from Karakata) got correct answers in causes of HIV/AIDS, $60 \%$ from Libermann, $45.8 \%$ from Karakata got correct answers in ways of preventing against HIV/AIDS, and 62.5\% from Libermann and 52.5\% from Karakata got correct answers in effects of HIV/AIDS.

Post-Test Results. The same pupils who participated on the pre-test evaluation were given computers installed with the developed interactive multimedia enhanced content to use for three months. They responded to the same 10-item questionnaires to investigate the level of knowledge regarding HIV/AIDS awareness education. Out of the 80 pupils who did the test, 90\% from Libermann and 79\% from Karakata got correct answers in Causes of HIV/AIDS, 87\% from Libermann and 83\% from Karakata got correct answers in Prevention against HIV/AIDS, and 91.7\% from Libermann and 85\% from Karakata got correct answers in Effects of HIV/AIDS. The results shows that level of knowledge among pupils after using the interactive multimedia has been enhanced in the three knowledge areas (causes, prevention and effects) of HIV/AIDS education as demonstrated in Figure 6 and Figure 7. Therefore, the interactive multimedia content is effective in enhancing HIV/AIDS awareness education based on the results obtained.

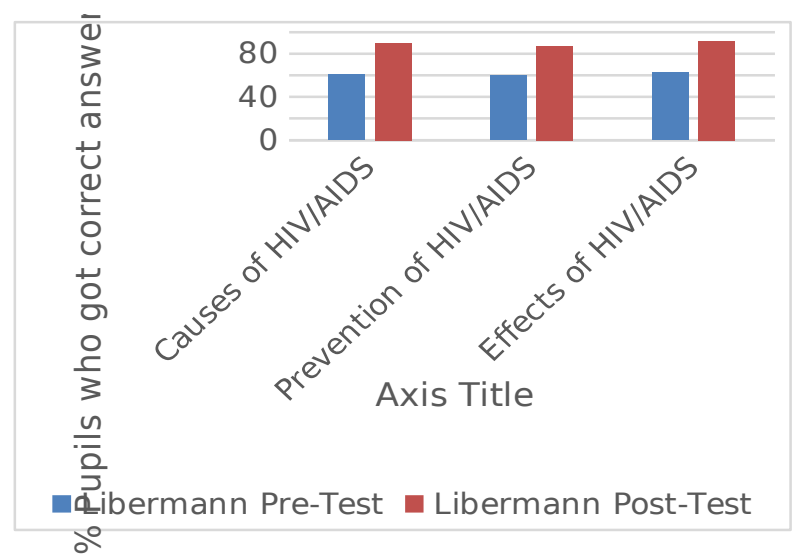


Fig. 6. Comparison of pre-test and post-test results at Libermann School

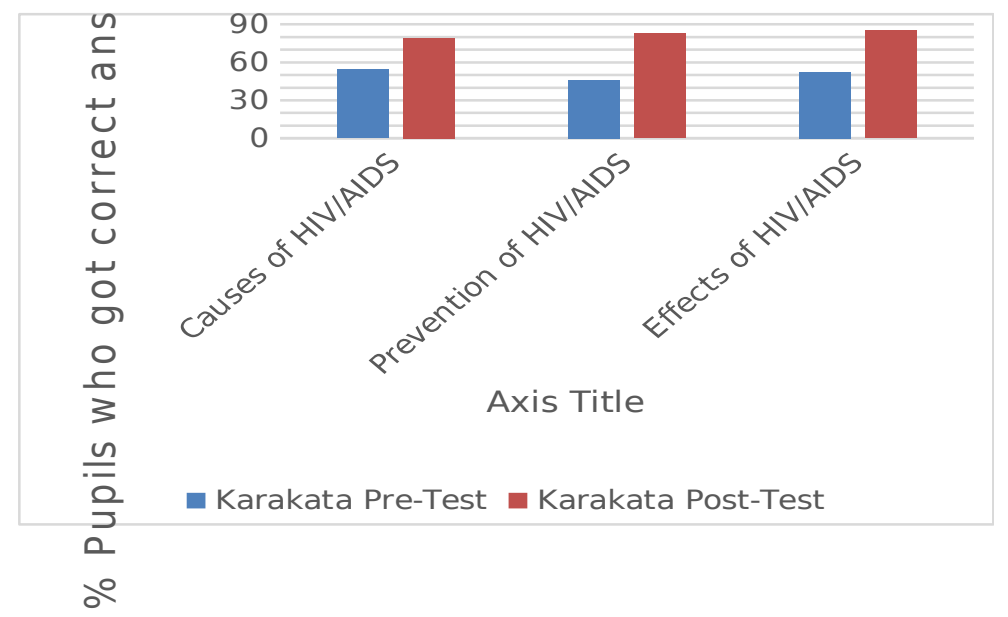

Fig. 7. Comparison of pre-test and post-test results at Karakata School

\section{Conclusion and Recommendations}

The findings from this paper provide a new understanding of how ICT can help to improve HIV/AIDS awareness to children. Specifically, the paper has demonstrated that multimedia enhanced contents are easy to use, useful and effective tool for enhancing HIV/AIDS awareness to children. However, one of the notable limitations of this study is that the multimedia enhanced content was tested using a small population of 8 teachers and 80 pupils in urban schools where smartphones usage and Internet coverage are high. It would be interesting to assess the effectiveness of the developed system using a large population of users including those in rural schools. Another limitation of the study was that the multimedia enhanced content was used effectively for a period of a period of three months (August - October) and then tested for effectiveness. Future research can allow many users to use the multimedia enhanced content for at least one academic year before evaluation. The developed multimedia enhanced contents were deployed to be accessible online in TanSSeL and CD only. Further studies can extend the multimedia enhanced content to be accessible in other platforms such as television and mobile devices in android, iOS, Windows, and Blackberry.

\section{References}

UNAIDS, “UNAIDS Data 2017,” Jt. United Nations Program. HIV/AIDS, pp. 1-248, 2017.

2 UNAIDS, World AIDS Day Report. 2011.

3 PMO, "Tanzania third national multi-sectoral strategic framework for HIV and 
AIDS.," 2013.

$4 \quad$ WHO, "HIV prevention strategy for Tanzania mainland," 2012.

$5 \quad$ N. Bilinga, M., \& Mabula, "Teaching sexuality education in primary schools in Tanzania : Challenges and implications.,” J. Educ. Pract., vol. 5, no. 27, pp. 21-31, 2014.

R. H. Materu, "Towards gender-sensitive theological responses to HIV and AIDS : a critical study of the HIV and AIDS policy and programmes of the Northern Diocese of the Evangelical Lutheran Church in Tanzania.,” University of KwaZulu-Natal, 2011. B. Rushahu, "Assessment of HIV/AIDS and life skills delivery in primary schools in Tanzania.,” World J. Educ., vol. 5, no. 1, pp. 131-143, 2015.

J. Rishante, “Audience Perception of Multi-Media Approaches Towards HIV / AIDS Campaign in South-South Nigeria,” Int. J. Asian Soc. Sci., vol. 3, no. 3, pp. 727-740, 2013.

M. Z. M. Zin, A. A. Sakat, N. A. Ahmad, and A. Bhari, "Relationship Between the Multimedia Technology and Education in Improving Learning Quality,” Procedia Soc. Behav. Sci., vol. 90, no. InCULT 2012, pp. 351-355, 2013.

W. F. Chuang, T. Y., \& Chen, "Effect of computer based video games on children: An experimental study.,” J. Educ. Technol. Soc., vol. 12, no. 2, pp. 1-10, 2009. H. R. Arifin, "Developing English Interactive Multimedia Students ' E - Worksheet for Fourth Graders of Elementary School,” vol. IX, no. October, pp. 73-83, 2014. Q. Suleman, "Role of Educational Technology at Primary School Level In District Karak ( KHYBER PUKHTUNKHWA ),” vol. 1, no. 3, 2011. A. Dias, "Technology enhanced learning and augmented reality: An application on multimedia interactive books,” Int. Bus. Econ. Rev., vol. 1, no. 1, p. 69-79., 2009. A. Malik, S., \& Agarwal, "Use of multimedia as a new educational technology tool-A study.,” Int. J. Inf. Educ. Technol., vol. 2, no. 4, pp. 468-471, 2012. M. Saad, S., Dandashi, A., Aljaam, J. M., \& Saleh, "The multimedia-based learning system improved cognitive skills and motivation of disabled children with a very high rate,” Int. forum Educ. Technol. Soc., vol. 18, no. 2, pp. 366-379, 2015. M. Shilpa, S., \& Sunita, "A study about role of multimedia in early childhood education.,” Int. J. Humanit. Soc. Sci. Invent., vol. 2, no. 6, pp. 80-85, 2013. J. Kizito, B., \& Suhonen, "Survey on ICT for HIV/AIDS Preventive Education: Are the teenagers forgotten in developing countries?,” J. Emerg. Trends Comput., pp. 263275, 2011.

18 K. T, "A design and development of e-l earning content for multimedia technology using multimedia game,” Int. J. Softw. Eng. Appl., vol. 4, no. 6, pp. 61-69, 2013. R. W. Krishna, S., Francisco, B. D., Balas, E. A., Konig, P., Graff, G. R., \& Madsen, "Internet-enabled interactive multimedia asthma education program: A randomized trial,” J. Pediatr., vol. 111, no. 3, p. 503-510., 2003. S. Walsham, G., \& Sahay, "Research on information systems in developing countries: Current landscape and future prospects.,” Inf. Technol. Dev., vol. 12, no. 1, pp. 7-24, 2006. M. Clarke, "Reflection: Journals and Reflective Questions: a Strategy for Professional Learning.,” Aust. J. Teach. Educ., vol. 29, no. 2, p. 1-14., 2004. "eLSE Methodology: A systematic approach to the e-Learning systems evaluation," 
Educ. Technol. Soc., vol. 9, no. 4, pp. 42-53, 2006. 